\title{
Statistical optimization of enzymatic degradation process for oil palm empty fruit bunch (OPEFB) in rotary drum bioreactor using crude cellulase produced from Aspergillus niger EFB1
}

\begin{abstract}
Oil palm empty fruit bunch (OPEFB) was pretreated with $2 \%(\mathrm{v} / \mathrm{v}) \mathrm{HNO} 3$ and degraded by Aspergillus niger EFB1 crude cellulase. Through 2 Level Factorial Design (2LFD), it was found that OPEFB concentration, temperature, incubation time, concentration of Tween 80 and agitation speed have significant effect in reducing sugar production. A standard Response Surface Methodology (RSM) design known as Central Composite Design (CCD) was used to optimize the enzymatic degradation condition of OPEFB in rotary drum bioreactor. Reducing sugar level of $1.183 \mathrm{~g} / \mathrm{L}$ was obtained with the following optimized degradation conditions: $1.95 \%(\mathrm{w} / \mathrm{v})$ OPEFB, $0.5 \%(\mathrm{v} / \mathrm{v})$ Tween $80,55{ }^{\circ} \mathrm{C}, 87.5 \mathrm{rpm}$ in the incubation period of 3 days and $16 \mathrm{~h}$. The optimal degradation condition improved reducing sugar production by 1.07 fold compared to that before optimization in shake flasks culture. The optimization strategy of enzymatic degradation of OPEFB inside rotary drum bioreactor led to increase in glucose, xylose, arabinose, galactose and mannose production by 3, 2.5, 1.64, 19.37 and 22.52 fold, respectively. The improvement in reducing sugar and polyoses production were comparable with the reduction in OPEFB cellulose and hemicellulose content by $89.32 \%$ and $48.17 \%$ respectively after enzymatic degradation in optimized condition.
\end{abstract}

Keyword: 2 Level factorial design; Central composite design; Response surface methodology; Reducing sugar 